\title{
Styles of coping with stress presented by female and male students of Physical Education during the pandemic

\author{
A. Samełko a, ${ }^{*}$ (D) M. Szczypińska a, M. Guszkowska b
}

a Department of Pedagogy and Psychology of Physical Culture, Józef Piłsudski University of Physical Education in Warsaw, Warsaw, 00-968, Poland

${ }^{\mathrm{b}}$ Department of Occupational Therapy, Józef Piłsudski University of Physical Education, Warsaw, 00-968, Poland

*Corresponding author Ph +48 2283404 31(466); Email: al.samelko@gmail.com

DOI: https://doi.org/10.34256/ijpefs2049

Received: 16-12-2020, Revised: 23-12-2020; Accepted: 25-12-2020; Published: 25-12-2020

Abstract: The aim of the study was to determine the intensity of coping strategies used by students of Physical Education during a pandemic. Women and men were compared in terms of strategies considered positive and negative. The study used the psychological tool: Inventory for the Measurement of Coping with Stress. The participants were students of Physical Education (aged 25.69 \pm 5.908); 26 women, 28 men. Results: the examined women show a higher intensity of both positive and negative coping strategies. The most common strategy among students is positive re-evaluation. Conclusions: The surveyed students experiencing difficult situations choose rather positive than negative strategies of coping with the problem. Women showing a higher level of coping strategies may be more aware of a difficult situation or experience a pandemic more intensely in relation to men.

Keywords: Cessation sport activity, Coronavirus, Men, Women
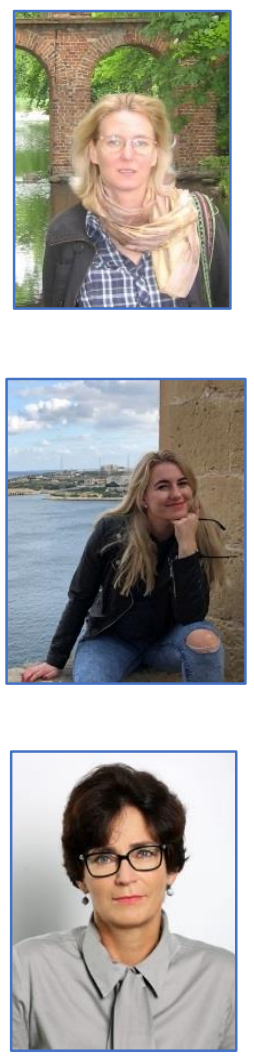

Prof. Monika Guszkowska Professor of physical culture, PhD; head of the Chair of Occupational Therapy at the Józef Piłsudski University of Physical Education in Warsaw, Poland; author of 4 scientific monographs on the relationship between physical activity and psyche, scientific editor of 3 scientific monographs, author of many scientific articles in the field of psychology of physical activity, health psychology and sport psychology.

\section{Introduction}

Coping mechanisms are some sort of "survival skills" which/whose people use to deal with the stress, pain, and natural changes which they experience in their lives. There are stands out are positive and negative coping mechanisms. Negative coping mechanisms may include denial, self-harm and addiction, while positive coping mechanisms entail? the individual's ability to maintain a positive disposition and healthy lifestyle, establishing structure support and creating effective and creative pathways [1].

In coping, requirements are perceived as difficult to meet or exceeding individual abilities. Coping in the literature is deliberate cognitive and behavioral activities aimed at meeting the expectations of the external and internal environment. Depending on the type of problem, coping is expressed in two main functions: dealing with the problem that causes suffering (problem-focused coping) and regulating emotions (emotion-oriented coping) [2, 3]. Mechanism 
can be divided into more and less optimal. In order to successfully adapt to the requirements of the environment, various coping mechanisms have been developed. There are those that are beneficial, but also those that bring negative consequences in the long run. In terms of the impact on physical and mental health, coping styles are divided into positive and negative $[4,5]$.

Positive coping is associated with better mental health outcomes, while negative coping is associated with psychological problems [6, 7]. Positive coping styles, such as problem-solving attempts, information seeking, and social support, focus on actively trying to cope with stress and change the problematic situation. The hallmarks of negative coping styles are avoidance, wishful thinking, and substance use. Negative coping focuses on the emotions triggered by the stressor, not the stressor itself [8]. Participants' ways of problem solving and seeking help were shown to be important mediators of stress and subjective well-being, especially positive affect [9].

Recently, many articles have been written related to various psychological variables, their intensity and changes in relation to the current norms during pandemic the Covid-19 [10]. Some of them seem to be pragmatic, as scientific knowledge has been translated into psychoeducational materials and used in healthcare [11]. Based on the growing number of 2019 new coronavirus disease (COVID-19) cases, the World Health Organization's Extraordinary Committee announced a global health emergency on January 30 [12]. The COVID-19 outbreak poses a great threat to public health worldwide. This mental distress has been mainly described as sleep disturbance, symptoms of anxiety and depression, post-traumatic stress disorder, decision incapacity, and even somatic symptoms [13]. In last time an online study of mental health during the COVID-19 pandemic found that coping style was one of the factors influencing mental stress, i.e. Participants with negative coping styles had higher levels of mental distress such as nervousness, hopelessness and restlessness [14]. Therefore, coping style may weaken the link between perceived stress and emotional stress during the outbreak of the COVID-19 pandemic [12].

The last few decades have brought many studies suggesting that men and women show different trajectories of psychological symptoms [15]. For example, female crime scene officers tend to engage in more emotional support, instrumental support, and positive reformulation than in the analysis of coping paths, a positive correlation was found between exposure to stress and coping with avoidance [16]. Moreover, coping avoidance has been shown to have an indirect effect on the relationship between stress and well-being. A systematic review in research found that coping avoidance strategies negatively affected psychological outcomes [17]. In the case of students, the statistical analysis of the Mini-COPE data showed significant differences between men and women in particular years of the study. In the first year, women more often chose strategies related to turning to religion, seeking emotional support, and seeking instrumental support than men. Moreover, women were characterized by a higher level of stress than men. Men are more likely to use psychoactive drugs and resort to a sense of humour to deal with stress [18]. Many factors influenced in analyzes focused on mental health [19-21]. In the analyzes below, positive strategies are considered to be those that involve coping actively with the problem, and negative strategies are associated with a style of avoidance [8]. The aim of the study was to show the differences in strategies used by women and men in a pandemic situation.

\section{Materials and Methods}

\subsection{Participants}

The study group consisted of 54 extramural students of Physical Education, aged 19 to 40 $(M=25.69 ; S D=5.908)$, including 26 women (48.1\%) and 28 men (51.9\%). They practiced recreational sports and took up paid work.

\subsection{Measurement}

Inventory for the Measurement of Coping with Stress (Mini COPE) [22] in the Polish adaptation of Juczyński and Ogińska-Bulik [23] consists of 14 coping strategies; active counseling, planning, positive reevaluation, acceptance, sense of humor, turn to religion, seeking emotional support, seeking instrumental support, dealing with something else, denial, discharge, taking psychoactive substances, ceasing activities, self-blame. The Polish language version is characterized by a satisfactory split-half reliability of (0.86). The accuracy of the tool is confirmed by the results of the factor analysis.

\subsection{Procedures}

The research was conducted in the form of an on-line survey on the platform 
https://www.survio.com/pl/ in April 2020. during the COVID-19 pandemic. In Poland, a ban on sports activities has been introduced. All subjects participated in the study during the period of the ban.

\section{Results and Discussion}

\subsection{Statistical analizes}

Since the variables did not meet the requirements of the normal distribution, the U MannWhitney test was used to determine differences between the groups. The limit of the confidence interval was set at the level of $p<0.1$ (which meant a tendency for the dependence of the variables).

\subsection{Results of coping strategies with stress}

Table 1 Comparing the group of women and men in terms of significant coping strategies.

\begin{tabular}{|c|c|}
\hline \multicolumn{2}{|c|}{ Coping style } \\
\hline Acceptance & $288.5^{* *}$ \\
\hline Seeking emotional support & $242.5^{* * *}$ \\
\hline Seeking instrumental support & $224^{* * *}$ \\
\hline Dealing with something else & $283.5^{* *}$ \\
\hline Taking psychoactive substances & $325^{*}$ \\
\hline Ceasing to act & $325^{*}$ \\
\hline Positive re-evaluation & $296.5^{*}$ \\
\hline
\end{tabular}

$\mathrm{p}<0.1^{*}, \mathrm{p}<0.05 * *, \mathrm{p}<0.01 * * *$

The above table 1 presents only those strategies that turned out to be statistically significant from the point of view of differences between the gender of the respondents. The students male and female showed the greatest differences in seeking emotional and instrumental support.

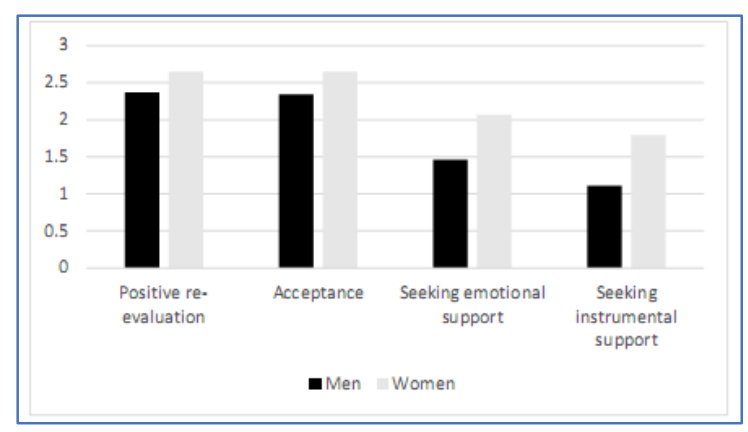

Fig.1. Positive coping of students male and students female
The figure shows the differences between female and male students. Women scored higher on each of the selected aspects of the coping strategy (Figure $1 \& 2$ ).

In strategies for negative coping, women show higher scores on all variables. There are significant differences in each of the strategies.

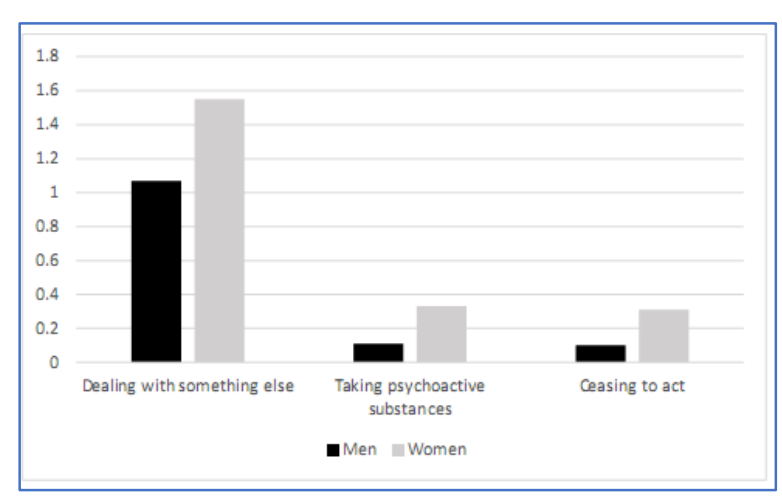

Fig. 2. Negative coping of students male and students female

\subsection{Discussion}

Our research presents the results of coping with the example of students from the Faculty of Physical Education during a pandemic. Similar analyzes carried out on another group showed a relationship between maladaptive or negative coping and higher levels of depression and anxiety [24-26]. Adaptive emotional regulation, such as positive representation and evaluation, act as a buffer between subjective perception of a pandemic situation and possible fear of the virus [27]. Differences in how people deal with events make people more susceptible to the negative consequences of stress [28]. For example, the impact of negative life events on depression was greater among those who adopted more negative coping strategies, such as worrying about problems instead of solving them [29]. Likewise, among women who adopted more negative coping strategies, such as passive acceptance and wishful thinking, high scores on negative life events were associated with significant increases in depression and anxiety symptoms [30,31]. The outbreak of the coronavirus (COVID-19) pandemic posed a huge threat to the physical and mental health of the general population. The results showed that negative coping strategies increased emotional suffering [13]. Some studies have highlighted the positive effects of social and family support on mental health $[32,33]$. In our study, women showed a greater willingness to admit that they were using the coping 
process, and therefore experiencing stress, more than men.

On the basis of other reports, it is assumed that resources (generalized immune resources) make it possible to avoid stressors or (when it is impossible) to cope with the tension generated by them. Maybe this (in our research) is why men showed lower scores in all coping strategies that significantly differentiated them from women [34].

Other studies in the early months of the pandemic reported that young people were using coping strategies such as denial of the problem, emotional discharge, substance use, stopping action, and blaming themselves for the situation. It seems interesting that such coping strategies are used by women and men, for whom the current situation may pose a threat to health, job loss, or interrupting education [35].

If you take a closer look at the gender differences, you notice that men and women function differently in the face of everyday difficulties or crisis situations. There is evidence that men and women deal with stress in different ways. For example, a metaanalysis showed that women prefer to focus on emotions as a coping strategy. Moreover, men are less likely than women to seek help with psychological issues. Research shows that men and women show significant differences in some aspects of coping and seeking help [36].

The above research was carried out on extramural students who take up gainful employment and participate in weekend activities consistent with the study program. Students could experience additional stress related to job insecurity and, consequently, financial problems. The lack of a sense of stability equates to the failure to meet one of the basic human needs, namely the need for security. Research findings show that coping strategies play a moderating function in the relationship between job insecurity and mental health. It turns out that the burden of coping with disengagement strategies is more important than the buffering role of engagement strategies. On this basis, women implement more coping strategies, which have more positive mental health outcomes [37]. Likewise, more women than men in our study have implemented coping strategies.

In the relationship between job insecurity and mental health, the most important strategies are those related to social interaction inside and outside the organization, and these are the main strategies used by women. It follows that strengthening rich social relations in the work environment and beyond is a guarantee of well-being [37].

\section{Conclusion}

The pandemic is an extremely difficult situation. It is associated with many difficulties that are not conducive to private and professional life, as well as meeting the need for exercise. It is worth remembering about constructive ways of coping with stress.

Regular physical exercise seems to be important, as it counteracts difficulties in regulating mood and increases the level of mental energy. Unfortunately, the quarantine, in which the respondents also participated, inhibited all manifestations of group activity, in the open air or in sports facilities, allowing only independent exercise at home. One can only guess that the effects of a pandemic may be felt for a long time and lead to health problems through reduced activity and deterioration of mental well-being.

People may react differently to the problem of a pandemic. It should be assumed that this is an objectively difficult situation. However, specific problems relate to individual needs and difficulties in the functioning of the individual. Some experience economic difficulties, others - uncertainty about the future and difficulties in social relations due to the lack of physical proximity of others. Despite the evident threat to each circumstance, a pandemic may be associated with different and thus incomparable experiences. Therefore, it is worth studying (measuring, controlling) psychological variables, such as the styles of coping with stress, but also mental health or affective states. Supervision over factors changing in time of danger should translate into social awareness and at a later stage ensure prevention aimed at the most vulnerable social groups. In our study, men are such a group, which may suggest that it is the male ones that are exposed to greater difficulties and that they would need to be provided with access to mental well-being factors, such as social support.

\section{References}

[1] P.C. Custodio, L.C. Siy. Needs, difficulties and coping mechanisms of women as professionals and as managers of households. Asia Pacific Journal of Multidisciplinary Research. 5 (2) 
(2017) 147-155.

[2] A. Fitzell, K.I. Pakenham. Application of a stress and coping model to positive and negative adjustment outcomes in colorectal cancer caregiving. Psycho-oncology. 19 (11) (2010) 1171-1178. DOI | PubMed

[3] R.S. Lazarus, S. Folkman, (1984) Stress, appraisal and coping, Springer, New York.

[4] S.L. Berman, W.M. Kurtines, W.K. Silverman, L.T. Serafini. The impact of exposure to crime and violence on urban youth. American Journal of Orthopsychiatry, 66 (3) (1996) 329-336. DOI । PubMed

[5] Y. Xie. Reliability and validity of the simplified coping style questionnaire. Chinese Journal of Clinical Psychology. 6 (1998) 114-115.

[6] G. Mark, A.P. Smith. Effects of occupational stress, job characteristics, coping, and attributional style on the mental health and job satisfaction of university employees. Anxiety, Stress, and Coping. 25(1) (2012) 63-78. DOI । PubMed

[7] G. Mark, A.P. Smith. Occupational stress, job characteristics, coping, and the mental health of nurses. British Journal of Health Psychology. 17(3) (2012) 505-521. DOI I PubMed

[8] K.M. Nowack. Coping style, cognitive hardiness, and health status. Journal of Behavioral Medicine. 12(2) 1989 145-158. DOI I PubMed

[9] G.W. Ryu, Y.S. Yang, M. Choi. Mediating role of coping style on the relationship between job stress and subjective well-being among Korean police officers. BMC Public Health. 20 (2020) 470. DOI

[10] N. Extremera N. Coping with the stress caused by the COVID-19 pandemic: future research agenda based on emotional intelligence. Journal International Journal of Social Psychology. Revista De Psicología Social. 35(3) (2020) 631638. DOI

[11] S.R. Fiorim, S.R.F. Enumo, J.N. Weide, V. Ecch, M.F. de Araujo, W.L. Machado. Coping with stress in times of pandemic: a booklet proposal. Estudos de psicologia. Campinas. 37 (2020). DOI

[12] L. Yan, Y. Gan, X. Ding, J. Wu, H. Duan. The relationship between perceived stress and emotional distress during the COVID-19 outbreak: Effects of boredom proneness and coping style. Journal of Anxiety Disorders. 77 (2021) 102328. DOI I PubMed

[13] A.N. Master, X. Su, S. Zhang, W. Guan, J. Li. Psychological impact of COVID-19 outbreak on frontline nurses: A cross-sectional survey study, Journal of Clinical Nursing, 29(21/22) (2020) 4217-4226.
[14] H. Wang, Q. Xia, Z. Xiong, Z. Li, W. Xiang, Y. Yuan, Z. Li. The psychological distress and coping styles in the early stages of the 2019 coronavirus disease (COVID-19) epidemic in the general mainland Chinese population: A webbased survey. PloS One. 15(5) (2020). DOI I PubMed

[15] R. Rojiani, J.F. Santoyo, H. Rahrig, H.D. Roth, W.B. Britton. Women Benefit More Than Men in Response to College-based Meditation Training. Frontiers in Psychology. 8 (2017) 551. DOI । PubMed

[16] E. Arble, A.M. Daugherty, B.B. Arnetz. Models of first responder coping: police officers as a unique population. Stress Health. 34(5) (2018) 612-621. DOI I PubMed

[17] L. Sherwood L, S. Hegarty, F. Vallieres, P. Hyland, J. Murphy, G. Fitzgerald, T. Reid, Identifying the key risk factors for adverse psychological outcomes among police officers a systematic literature review. Journal of Traumatic Stress 32(5) (2019). DOI

[18] K. Mocny-Pachońska, A. Trzcionka, R.J. Doniec, S. Sieciński, M. Tanasiewicz. The Influence of Gender and Year of Study on Stress Levels and Coping Strategies among Polish Dental. Medicina. 56 (2020) 531.

[19] G.A. Cañadas-De la Fuente, E. Ortega, L. Ramirez-Baena, E.I. de la Fuente-Solana, C. Vargas, J.L. Gómez-Urquiza. Gender, marital status, and children as risk factors for burnout in nurses: A meta-analytic study. International Journal of Environmental Research and Public Health, 15(10) (2018) 2102. DOI I PubMed

[20] 21.A.K. Sadati, S. Hemmati, F. Rahnavard, K.B. Lankarani, S.T. Heydari. The impact of demographic features and environmental conditions on rates of nursing burnout. Shiraz E Medical Journal. 17(3) (2016) e37882. DOI

[21] H. Tehrani, T. Rakhshani, Z.D. Shojaee, S.M. Hosseini, S. Bagheriyan. Analyzing the relationship between job stress to mental health, personality type and stressful life events of the nurses occupied in Tehran 115 emergency. Iranian Red Crescent Medical Journal. 15(3) (2013) 272- 273. DOI I PubMed

[22] C.S. Carver, M.F. Scheier, J.K. Weintraub. Assessing coping strategies: A theoretically based approach, Journal of Personality and Social Psychology, 56 (1989) 267-283. DOI । PubMed

[23] Z. Juczyński, N. Ogińska-Bulik, (2009) NPSR Narzędzia Pomiaru Stresu i Radzenia Sobie ze Stresem[Stress Measurement and Stress Management Tools]. PTP, Warsaw.

[24] L.V. Doering, K. Dracup, M.A. Caldwell, D. K. 
Moser, V.S. Erickson, G. Fonarow, M. Hamilton. Is coping style linked to emotional states in heart failure patients? Journal of Cardiac Failure. 10(4) (2004) 344-349. DOI

[25] R. Dyson, K. Renk. Freshmen adaptation to university life: Depressive symptoms, stress, and coping. Journal of Clinical Psychology. 62(10) (2006) 1231-1244. DOI I PubMed

[26] J.S.R. Mahmoud, R.T. Staten, L.A. Hall, T.A. Lennie. The relationship among young adult college students' depression, anxiety, stress, demographics, life satisfaction, and coping styles. Issues in Mental Health Nursing. 33(3) (2012) 149-156. DOI I PubMed

[27] S.M. Jungmann, M. Witthöft. Health anxiety, cyberchondria, and coping in the current COVID19 pandemic: Which factors are related to coronavirus anxiety? Journal of Anxiety Disorders. 73 (2020) 102239. DOI | PubMed

[28] M. Vollrath, S. Torgersen. Personality types and coping. Personality and Individual Differences. 29(2) (2000) 367-378. DOI

[29] M.G. Sawyer, S. Pfeiffer, S.H. Spence. Life events, coping and depressive symptoms among young adolescents: A one-year prospective study. Journal of Affective Disorders. 117 (1/2) (2009) 48-54. DOI I PubMed

[30] J.A. Blalock, T.E. Joiner. Interaction of cognitive avoidance coping and stress in predicting depression/anxiety. Cognitive Therapy and Research. 24(1) (2000) 47-65. DOI

[31] Y. Yu, L. Peng, B. Liu, Y. Liu, M. Li, L. Chen, J. Li. The effects of anxiety and depression on stressrelated growth among Chinese army recruits: Resilience and coping as mediators. Journal of Health Psychology. 21(9) (2016)1884-1895. DOI I PubMed

[32] S.H. Hamaideh. Occupational stress, social support, and quality of life among Jordanian mental health nurses. Issues in Mental Health Nursing. 33(1) (2012) 15- 23. DOI I PubMed

[33] S. Kutluturkan, E. Sozeri, N. Uysal, F. Bay. Resilience and burnout status among nurses working in oncology. Annals of General Psychiatry. 15 (2016) 33. DOI

[34] C.J. Holahan, R.H. Moos. Personality, coping, and family resources in stress resistance: $A$ longitudinal analysis. Journal of Personality and Social Psychology. 51(2) (1986) 389-395. DOI I PubMed

[35] M. Talarowska, J. Chodkiewicz, N. Nawrocka, J. Miniszewska, P. Biliński. Mental Health and the SARS-COV-2 Epidemic-Polish Research Study. International Journal of Environmental Research Public Health. 17 (2020) 7015. DOI I PubMed

[36] L. Liddon, R. Kingerlee, J. A. Barry. Gender differences in preferences for psychological treatment, coping strategies, and triggers to help-seeking. British Journal of Clinical Psychology. 57 (1) (2017) 42-58. DOI I PubMed

[37] S. Menéndez-Espina, J.A. Llosa, E.Agulló-Tomás, J. Rodriguez- Suárez, R. Sáiz-Villar, H. F. Lahseras-Díez. Job Insecurity and Mental Health: The Moderating Role of Coping Strategies From a Gender Perspective. Frontiers in Psychology. 10 (2019) 286. DOI I PubMed

\section{Acknowledgement}

Nil

\section{Funding}

Nil

\section{Authors Contribution}

Individual contributions are as follows: A. Samełko Study Design, Manuscript Preparation, Review \& Editing. Study Design, Manuscript Preparation; M. Szczypińska \& M. Guszkowska. All authors have read and approved the manuscript.

\section{Ethics Approval}

Not Applicable

\section{Conflict of interest}

Nil

Availability of data and material

No additional data are available

Informed consent

Written consent were obtained from the participants

\section{About The License}

(C) The author(s) 2020. The text of this article is open access and licensed under a Creative Commons Attribution 4.0 International License 